\title{
Dose constraints, What are they now?
}

\author{
T. $\mathrm{LAZO}^{1}$
}

(Manuscript received 10 November 2004, accepted 4 March 2005)

ABSTRACT The concept of a source-related dose constraint was first introduced in ICPR publication 60. The idea was to provide a number that individual exposures from a single, specific source should not exceed, and below which optimisation of protection should take place. Dose constraints were applied to occupational and public exposures from practices. In order to simplify and clarify the ICRP's recommendations, the latest draft, $\mathrm{RP05}$, presents dose constraints again, and with the same meaning as in publication 60. However, the dose constraints are now applied in all situations, not just practices. This new approach does provide simplification, in that a single concept is applied to all types of exposures (normal situations, accident situations, and existing situations). However, the approach and numerical values that are selected by regulatory authorities for the application of the concept, particularly in normal situations which are also subject to dose limits, will be crucial to the implementation of the system of radiological protection.

Key words: Dose constraint / ICRP / Optimisation

RÉSUMÉ Contraintes de dose, que sont-elles devenues ?

Le concept de contrainte de dose, lié à une source, a été présenté dans la publication 60 de la CIPR. L'idée était de donner une valeur numérique à ne pas dépasser pour les expositions individuelles provenant d'une source spécifique, et au-dessous de laquelle l'optimisation de la radioprotection doit être mise en œuvre. Les contraintes de dose étaient appliquées pour les expositions professionnelles et celles du public mais uniquement dans le cadre des Pratiques. Pour simplifier et clarifier ses recommandations, la CIPR, dans son dernier projet (RP05), propose toujours des contraintes de dose, avec la même définition que dans la publication 60 , à ceci près que les contraintes de dose s'appliquent désormais à toutes les situations, et pas seulement dans le cas des pratiques. Cette nouvelle approche est réellement une simplification, en ce sens qu'un seul concept s'applique dans toutes les situations (normales, accidents, existantes). Mais, la sélection des valeurs numériques, et l'approche pratique retenue par les autorités de radioprotection pour l'application de ces contraintes seront cruciales pour la mise en œuvre du système de radioprotection, tout particulièrement pour les situations «normales » pour lesquelles les limites de dose resteront applicables.

I guess that it was Bob Dylan who immortalised the words, "the times, they are a changin' ". Well, it's still true, and were we are going is still up for grabs.

The work begun in 1999 at the ICRP to develop and publish new recommendations is coming to a close, and things do seem to have evolved.

1 OECD; NEA, La Seine St Germain, 12 boulevard des Iles, 92130 Issy-les-Moulineaux, France 
Pushed by such things as declining social trust in science and technology, the ICRP has widened its principle of Justification, placing the decision to justify essentially on governmental decision makers. Decisions on whether or not something is justified, the ICRP now says, will be made with input from the technical side, but probably mostly based on social needs and concerns. I must agree that we, the technical community can, to the best of our scientific abilities, identify the quantitative risk associated with a particular activity (i.e. irradiating gemstones, or going to a radium spa). But a person's view of whether or not a particular risk is acceptable is not founded on science. Some people jump from planes, others don't! So we can put risks into numbers, and into perspective with other risks, and even talk about the costs and marginal costs of protection, but justification then lies with society through government. Democracy in action!

Another evolution in the proposed ICRP recommendations is the concept of the dose constraint. The concept of dose constraints was introduced in publication 60 as a means to assure that the optimisation process did not "create inequities", that is, exposing some much more than the average (i.e. a small number of highly exposed workers rather than a larger number less exposed workers). This concept is presented in paragraph 121 of publication 60 (ICRP, 1991).

This definition is further supplemented by other text in publication 60 describing how constraints should be used in the control of occupational exposure and of public exposure. Paragraph 144 discusses using well-managed practices to set occupational dose constraints. Paragraph 145 says that dose constraints should be fixed nationally or locally. Paragraph 147 suggests that both dose constraints and dose limits are needed as occupational protection tools. Paragraph 150 presents the meaning of occupational dose limits as the boundary between "unacceptable" and "tolerable". Paragraph 166 suggests that occupational dose constraints should not exceed $20 \mathrm{mSv}$ in a year. And paragraph 170 suggests that dose constraints should be used as tools to implement different levels of social judgement that will be inevitably found in different situations in different locations.

Publication 60 also discusses dose constraints in the context of public exposure. Paragraph 186 suggests that dose constraints should be set to assure that no critical group approaches the public dose limit. And paragraph 192 suggests that dose constraints for the public should be less than $1 \mathrm{mSv}$ in a year.

In general, these paragraphs characterise dose constraints as:

- ONLY applying to situations that are under control, called practices;

- being numerically less than dose limits;

- being established by national authorities; 
- having numerical values that are based on exposures that can be incurred in "well-managed operations", for occupational exposures, and based on fractions of the public dose limit depending upon the number of sources to which a critical group is exposed.

This concept in publication 60 is distinct from the protection of workers or the public in the case of accidents or already-existing situations. In these cases, the ICRP suggests the establishment of "reference levels", ABOVE which some remedial actions should be considered (paragraph 257). In the case of emergency situations, these were called intervention levels (paragraph 221). In the case of existing situations, such as exposure to radon, they were called action levels (paragraph 217). Below these reference levels, the Commission suggests that, in general, no protective actions would be needed.

\section{Dose constraints in the new draft ICRP recommendations}

As a result of criticisms that the publication 60 recommendations were somewhat incoherent, and in order to simplify and consolidate its recommendations, the Commission has now established in its new draft recommendations (I'll refer to these as RP05 which is currently on the ICRP web page: www.icrp.org) that ALL exposure situations will be conceptually addressed through the process of constrained optimisation. This seems to mean that dose constraints will be established for situations that are under control (formerly called practices), as well as for accident situations and existing situations (formerly called interventions). In all these situations, a dose constraint is then established above which exposures should not be allowed, and below which there should be optimisation. Exceeding these dose constraints would be considered as a FAILURE. This is explained in paragraphs 132 and 133 of the RP05 draft. It is also indicated in paragraph 137 that dose constraints may be used as a regulatory tool, so that exceeding a mandatory constraint may be a statutory offence.

This is an interesting evolution from the publication 60 concept of dose constraints regarding several aspects. In its publication 60 recommendations, the Commission considered, at lease implicitly, that dose limits were the most significant regulatory tool for the measurement of compliance. Now, it is explicitly said that a dose constraint may also be a regulatory tool.

The new recommendation proposes that in ANY situation, there can be a predefined exposure level above which exposures should not be allowed. One of the key precepts of publication 60 was that in "controlled", predictable situations, exposures could be actively controlled and could be limited, by regulation, to remain below a pre-defined value. Situations where doses could not be inherently 
prevented, such as an accident or a pre-existing situation due to natural exposures (i.e. radon), it was seen as practically impossible to pre-define a regulatory dose level above which individuals should not be allowed to exceed. As such, Intervention Levels were recommended, ABOVE which some action would be considered. Now, the Commission suggests that regulatory dose levels can be established in ALL situations such that planning, preparations and protective actions can be undertaken to effectively prevent individuals exceeding this predefined dose constraint. This can be used as a planning tool, as well as a retrospective tool for compliance.

This evolution is seen by many as being a significant change from previous ICRP philosophy. In particular, if exceeding a constraint is defined as a statutory offence, and it is felt that regulatory organisations will interpret dose constraints more as limits for compliance enforcement. As such, with the dose constraints being defined as no higher than a dose limit (in situations where limits are applicable), it is felt that regulatory requirements could become more strict, yet there is no new scientific evidence for such an effective lowering of exposure limits.

Also, the previous incarnation of dose constraints used to regulate intervention situations were built around establishing some sort of reference levels above which taking action should be considered, and below which action would most likely not be needed. National regulatory agencies and international organisations have since established their regulations and standards on this basis. Now, evolving to a concept of an "upper bound" in all situations below which optimisation should be performed could require a change of "mindset" in regulators and implementers alike, and perhaps regulatory and procedural modification.

\section{A possible approach to implementation}

However, would the implementation of this approach really change the implementation of radiological protection? Under the publication 60 approach, optimisation is required in all situations.

For practices, this meant the use of limits and constraints and the obligation to optimise protection below these values such that residual doses are as low as reasonably achievable. This approach is the same whether using the publication 60 philosophy or the new philosophy.

For interventions in accident situations, this means that the nature and duration of the intervention must be optimised to avert as much dose as reasonably 
achievable, that is, to prevent as much dose as possible when compared to not intervening. So, practically speaking, optimisation is again required.

For example, when predicted exposures begin to approach levels that would result in deterministic effects, intervention becomes required to prevent these exposures. This is, in effect, the establishment of a practical upper bound below which optimisation is required. A similar argument was implicitly used with regard to "significant" risk of stochastic effects when fixing intervention levels for evacuation or sheltering or use of stable iodine. Even at lower exposures, the obligation to optimise would generally result in protection solutions that avert more dose than suggested by the intervention level, thus effectively taking action BELOW the intervention level, as is suggested by the new concept.

When considering protection against exposure in existing situations, such as radon in homes, this same argument applies. The publication 60 approach led to national regulatory authorities generally establishing a level above which some actions to reduce exposures would become increasingly necessary. The new concept suggests that national regulatory authorities should use the ICRPrecommended dose constraint as an upper bound to then perform a sort of generic optimisation to establish a level below which dose reduction actions would not be considered, in general, necessary. The result of both approaches, in application, is then the same.

So, the approach proposed in RP05 seems to have some advantages:

- a single approach to all situations is easier to understand and to explain;

- the process is inherently driven by stakeholder involvement, at an appropriate level and with appropriate stakeholders;

- the process is inherently flexible in that it is based on optimisation, and optimisation ends when the stakeholders are in agreement on optimum protection so that appropriate solutions accounting for local considerations can be developed.

\section{Practical application choices will be the key}

The choice of numerical values for the new dose constraints is, however, a practical concern. As said earlier, the lack of new scientific evidence changing our current understanding of radiation risks suggests that there is no justification for tightening regulatory controls of exposures. However, particularly for controllable situations, with the clear statement that constraints should be less than regulatory limits, it is feared that occupational exposures could be constrained at a level of BELOW $20 \mathrm{mSv}$ per year, and that public exposures could be constrained at BELOW $1 \mathrm{mSv}$ per year. But it must be recalled that a dose constraint is a 
restriction on individual dose from a single-source whether a limit is related to the protection of an individual from all sources within a class of exposure.

It is also be noted that some concern has been voiced regarding the inherent loss of flexibility that would result from adopting an occupational dose constraint of $20 \mathrm{mSv}$ per year were to replace the current approach of dose limits set at $100 \mathrm{mSv}$ in 5 years, not to exceed $50 \mathrm{mSv}$ in any single year.

The practical application of the new recommendations by national regulatory authorities will thus be determinant as to whether these fears are justified or not.

\section{Conclusions}

The new dose constraint that the ICRP is proposing is consistent with the publication 60 approach (as an upper bound to optimisation), but is applied to a much broader spectrum of situations (All exposures situations as opposed to only controlled practices). I would call this a welcomed simplification and thus an advantage in terms of applicability and ease of presentation. However, depending upon how the new approach is interpreted and applied by regulatory authorities, it will cause more or less change "on the shop floor".

As discussions move from "ICRP philosophy" to "the application of ICRP recommendations", the topic of dose constraints will most likely occupy a central position for some time to come.

\section{REFERENCES}

ICRP Publication 60 (1991) 1990 recommendations of the International Commission on radiological Protection, Ann. ICRP 21 (1-3). 